\title{
Resource distribution influences positive edge effects in a seagrass fish
}

\author{
Peter I. Macreadie, ${ }^{1,2,6}$ Jeremy S. Hindell,${ }^{3}$ Michael J. Keough, ${ }^{1}$ Gregory P. Jenkins, ${ }^{1,4}$ \\ AND Rod M. CONNOLly ${ }^{5}$ \\ ${ }^{1}$ Department of Zoology, University of Melbourne, Parkville 3010 Australia \\ ${ }^{2}$ Victorian Marine Science Consortium, Queenscliff, Victoria 3225 Australia \\ ${ }^{3}$ Arthur Rylah Institute, Department of Sustainability and Environment, Heidelburg, Victoria 3084 Australia \\ ${ }^{4}$ Marine and Freshwater Fisheries Research Institute, Queenscliff, Victoria 3225 Australia \\ ${ }^{5}$ Australian Rivers Institute, Coast and Estuaries, and School of Environment, Griffith University, Gold Coast Campus, \\ Queensland 9726 Australia
}

\begin{abstract}
According to conceptual models, the distribution of resources plays a critical role in determining how organisms distribute themselves near habitat edges. These models are frequently used to achieve a mechanistic understanding of edge effects, but because they are based predominantly on correlative studies, there is need for a demonstration of causality, which is best done through experimentation. Using artificial seagrass habitat as an experimental system, we determined a likely mechanism underpinning edge effects in a seagrass fish. To test for edge effects, we measured fish abundance at edges $(0-0.5 \mathrm{~m})$ and interiors $(0.5-1 \mathrm{~m})$ of two patch configurations: continuous (single, continuous $9-\mathrm{m}^{2}$ patches) and patchy (four discrete $1-\mathrm{m}^{2}$ patches within a $9-\mathrm{m}^{2}$ area). In continuous configurations, pipefish (Stigmatopora argus) were three times more abundant at edges than interiors (positive edge effect), but in patchy configurations there was no difference. The lack of edge effect in patchy configurations might be because patchy seagrass consisted entirely of edge habitat. We then used two approaches to test whether observed edge effects in continuous configurations were caused by increased availability of food at edges. First, we estimated the abundance of the major prey of pipefish, small crustaceans, across continuous seagrass configurations. Crustacean abundances were highest at seagrass edges, where they were $16 \%$ greater than in patch interiors. Second, we supplemented interiors of continuous treatment patches with live crustaceans, while control patches were supplemented with seawater. After five hours of supplementation, numbers of pipefish were similar between edges and interiors of treatment patches, while the strong edge effects were maintained in controls. This indicated that fish were moving from patch edges to interiors in response to food supplementation. These approaches strongly suggest that a numerically dominant fish species is more abundant at seagrass edges due to greater food availability, and provide experimental support for the resource distribution model as an explanation for edge effects.
\end{abstract}

Key words: artificial seagrass; ecological flow; edge effects; food supplementation; habitat fragmentation; patchiness; pipefish; resource distribution model; spillover; Stigmatopora argus.

\section{INTRODUCTION}

Edges are boundaries between different habitat types (Strayer et al. 2003), and have long been recognized as regions of ecological significance (Clements 1907). The term "edge effect" was originally used to describe changes in species richness and abundance as landscapes shift from continuous to patchy habitat (Lay 1938). More recently, the term has been used to describe ecological changes that occur when moving from patch boundaries to patch interiors (Fagan et al. 1999). There

Manuscript received 9 October 2008; revised 1 September 2009; accepted 29 October 2009. Corresponding Editor: M. H. Carr.

${ }^{6}$ Present address: Department of Biological Sciences, University of Technology, Sydney 2007 Australia.

E-mail: petermacreadie@gmail.com has been a sharp increase in the frequency of edge effect studies over the past few decades, owing largely to global increases in habitat fragmentation and its propensity to increase the amount of edge habitat (Saunders et al. 1991, Fahrig 2003); edge effects are now the single most studied aspect of habitat fragmentation (Fazey et al. 2005). There remains, however, considerable uncertainty about the existence and intensity of edge effects, with recent reviews describing edge responses as unpredictable and seemingly idiosyncratic (Murcia 1995, Ries et al. 2004, Ewers and Didham 2006). This is thought to be because the majority of studies have not considered the mechanistic basis for edge effects, and have been largely correlative in nature (Murcia 1995).

Manipulative experiments offer the least ambiguous approach to determining the mechanisms that cause 
edge effects (e.g., Hovland et al. 1999, Cronin 2009), but examples are rare (Ries et al. 2004). This study uses both correlative and manipulative approaches to determine the mechanism causing edge effects in a seagrass fish. Seagrass habitats are ideal systems for testing ideas from landscape ecology because they form variable-sized patches and are relatively simple compared to their terrestrial counterparts in terms of species diversity and structural complexity (Robbins and Bell 1994). Furthermore, they are a critical marine habitat for commercially important fish and crustaceans (Jackson et al. 2001) and are under global decline as a result of habitat fragmentation (Duarte 2002, Orth et al. 2006). We use a series of experiments to test a resource distribution model that fish are more abundant at seagrass edges due to greater availability of food (crustaceans). We base our predictions on the model that seagrass limits edge permeability and restricts the flow of resources into seagrass patches, thus creating a distinction between edge and interior zones.

Seagrass beds reduce current flow and turbulence (Fonseca and Bell 1998, Hendriks et al. 2008), which affects the distribution of biota (e.g., Jackson et al. 2001, Hovel et al. 2002, Warry et al. 2009). Our study focuses primarily on the pipefish, Stigmatopora argus, which is a dominant fish species in seagrass of southeastern Australia (Jenkins et al. 1997b, Kendrick and Hyndes 2005). Pipefish are sit-and-wait ambush predators that hold on to seagrass blades to feed on passing planktonic crustaceans (Kendrick and Hyndes 2005). Food availability is considered to be a primary determinant of fish abundance in seagrass habitat (Connolly 1994a, $b$, Levin et al. 1997). Because seagrass plant structure influences edge permeability, it has the potential to intercept any planktonic crustaceans along seagrass edges (Hendriks et al. 2008), so it may be advantageous for pipefish to concentrate along edges. At edges, pipefish can have first access to planktonic crustaceans before they are potentially consumed by other fish and invertebrate predators within the seagrass (Bullard and Hay 2002). Furthermore, seagrass disrupts the formation of swarming crustaceans and this improves capture success by ambush predators (Flynn and Ritz 1999). Overall, this leads to the prediction that crustacean abundance (as a resource) will cause edge effects in pipefish.

Specifically, we test the following predictions: (1) fish in continuous seagrass habitat will be more abundant at edges than interiors (i.e., positive edge effects), but in patchy seagrass there will be no difference (i.e., no edge effect, because fish may "perceive" [sensu Attrill et al. 2000] patchy seagrass as consisting entirely of edge habitat); (2) the abundance of crustaceans (as a food resource) will be higher at edges than interiors in continuous seagrass habitat; and (3) increasing crustacean abundance (through supplementation) at interiors of continuous seagrass habitat will eliminate positive edge effects (i.e., fish will move from edges to interiors in response to food supplementation).

\section{Methods \\ Study site}

This study was done at Grassy Point $\left(38^{\circ} 07^{\prime} \mathrm{S}\right.$, $144^{\circ} 41^{\prime}$ E) in Port Phillip Bay, a large embayment in southeastern Australia. The most common seagrass, Heterozostera nigricaulis, occurs as bands of varying size and patchiness parallel to the shore (Blake and Ball 2001). Artificial seagrass patches were positioned on bare sand adjacent to a long band of natural seagrass, which acted as a source for fish colonization (see Plate $1)$.

\section{Construction of artificial seagrass}

Because seagrass habitat structure can vary with distance from edge (Bologna 2006), we used artificial seagrass in our experiments to remove potentially confounding microscale variation (e.g., seagrass density, length, thickness) and to control patch size, shape, orientation, position, and time of habitat establishment (Bostrom et al. 2006). Several studies have shown it is a good mimic of natural seagrass (e.g., Bell et al. 1985, Upston and Booth 2003). In addition, artificial seagrass avoids having to destroy or cultivate natural seagrass. Seagrass patches were produced using artificial seagrass units (ASUs) as building blocks, and were based on realistically sized patches found in Port Phillip Bay (Macreadie et al. 2009). ASUs were constructed by tying $5 \mathrm{~mm}$ wide green polypropylene ribbon to $1 \mathrm{~m}^{2}$ squares of steel mesh at a density of 3520 leaves $/ \mathrm{m}^{2}$. At each intersection of steel mesh (220 intersections $\left./ \mathrm{m}^{2}\right) ; 8 \times 1 \mathrm{~m}$ lengths of ribbon were tied to give 16 leaves of $\sim 0.45 \mathrm{~m}$ length. Shoot density and leaf length were based on mean estimates for this area (Jenkins et al. 1998). ASU patches were established on bare sand at a depth of 1-2 $\mathrm{m}$ below mean low water spring (MLWS). Each patch was separated by $30 \mathrm{~m}$, and located within $5-10 \mathrm{~m}$ of natural seagrass. Patches were left for three weeks to allow epiphyte growth and faunal colonization before sampling. Between experiments, any visible algae in ASUs were removed by hand prior to their redeployment. ASUs were always randomly assigned among experimental treatments.

\section{Fish sampling}

Fish were sampled with drop nets consisting of a buoyant top rope and weighted frame base $(0.5 \times 0.5$ and $1 \times 1 \mathrm{~m}$ in Experiment 1 and 3, respectively, with 2-m drop and 1-mm mesh size) and a handheld dip net (0.09 $\mathrm{m}^{2}$ ). Drop nets were released over an area of seagrass, and all fish trapped within the drop net were collected with a dip net, which was rerun until 10 continuous scoops yielded no fish. All sampling was done during daylight hours, which is when the strongest effects may be expected because it coincides with peak feeding times of the main fish groups sampled (Mosk et al. 2007). 

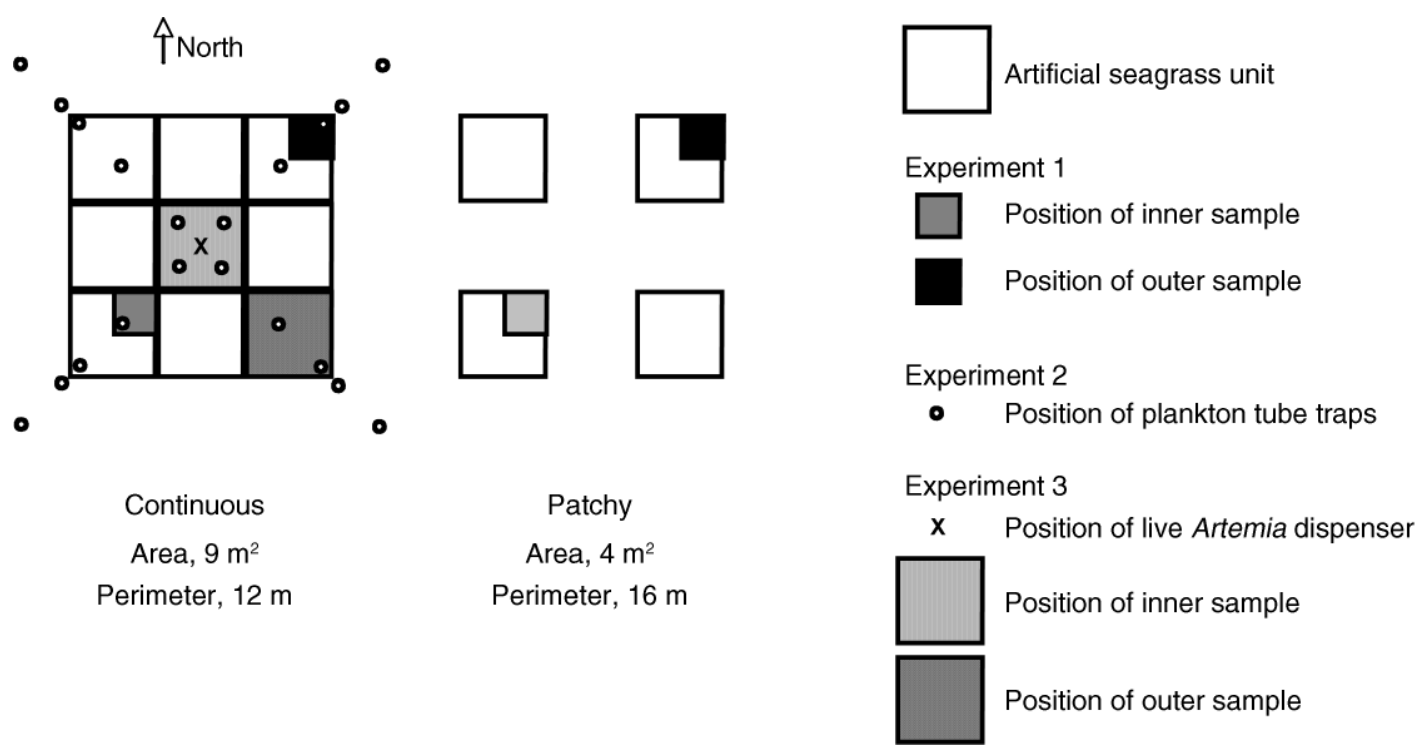

FIG. 1. Experimental layout showing the arrangement of artificial seagrass patches at our study site (Grassy Point, Victoria, Australia) and the areas sampled for each experiment. Patches were produced using $1-\mathrm{m}^{2}$ artificial seagrass units as building blocks, and these consisted of two configurations: continuous (C, single, continuous $9-\mathrm{m}^{2}$ patches); and, patchy (P, four discrete $1-\mathrm{m}^{2}$ patches within a 9- $\mathrm{m}^{2}$ area). In Experiment 1 we sampled "inner" and "outer" positions of continuous and patchy configurations for edge effects on fish abundance. In Experiment 2 we measured the abundance of fish food (planktonic crustaceans) across continuous patches to explain edge effects in fish abundance. In Experiment 3 we manipulated food abundance using live Artemia dispensers and then measured shifts in fish distributions across edges in response to food supplementation. The position of inner and outer samples changed between Experiments 1 and 3, and the sampling area was increased to ensure that food was primarily supplemented to "interior" samples and not outer samples.

\section{Experiment 1: edge effects on fish in seagrass}

To test for edge effects of fish in seagrass, we used a factorial design with two main factors: configuration and position. Configuration consisted of two seagrass patch types (Fig. 1): continuous (C), single, continuous 9- $\mathrm{m}^{2}$ patches; and, patchy $(\mathrm{P})$, four discrete $1-\mathrm{m}^{2}$ patches within the $9-\mathrm{m}^{2}$ area. Fish were sampled from two positions within each configuration: outer $(\mathrm{O}), 0-0.5 \mathrm{~m}$ from the edge corner of the corner ASU of a patch; and inner (I), 0.5-1 $\mathrm{m}$ from the edge corner of the corner ASU of a patch (Fig. 1). To account for potential orientation effects (Tanner 2003), the orientation of each position (i.e., northeast, southeast, northwest, or southwest) was randomly selected for each patch configuration. Three trials of the experiment were performed over the period January-March 2007, each with six replicates (one continuous replicate was lost in trial 1 following storm damage). Repeated trials of the experiment were necessary because of the large number of ASUs needed to replicate configurations in any one trial.

The response variable was fish density. Box plots and normal probability plots were used to test the assumptions of analysis of variance. The assumption of homogeneity of variances was met by transformation of data to $\log _{10}(x+1)$. Fish density data were analyzed only if a species occurred in $>10 \%$ of samples. Fish density was assessed in a four-factor partly nested
ANOVA, with trial (T) and configuration (C) as crossed factors, and individual plots (locations, L) nested within each CT combination. The fourth factor, position (P), was a within-plots factor, crossed with $\mathrm{C}$ and $\mathrm{T}$. Planned comparisons were made among continuous outer (CO), continuous inner $(\mathrm{CI})$, patchy outer $(\mathrm{PO})$, and patchy inner (PI) treatments. First, outer and inner samples from continuous configurations were compared (CO vs. CI) to test the prediction that samples that contain edge habitat will contain more fish than inner samples (i.e., positive edge effects). Second, we tested the prediction that outer and inner samples from patchy configurations (PO vs. PI) will not be different because they both contain "edge habitat." If both of these predictions were true, we then compared all samples that contained edge habitat (i.e., $\mathrm{CO}$ vs. PO, PI) to test the prediction that all edge habitats supported comparable fish density, regardless of habitat size.

\section{Experiment 2: spatial measurements of food abundance across seagrass edges}

To compare whether food abundance is greater at the edge than interior of patches we used a randomizedblock design with two main factors: position and orientation. Each block ( $n=10$ blocks/replicates) consisted of a single, continuous $9-\mathrm{m}^{2}$ seagrass patch constructed from ASUs (Fig. 1). Food abundance (plankton) was estimated from five positions along diagonals of each block (Fig. 1): 60 and $12 \mathrm{~cm}$ from the 

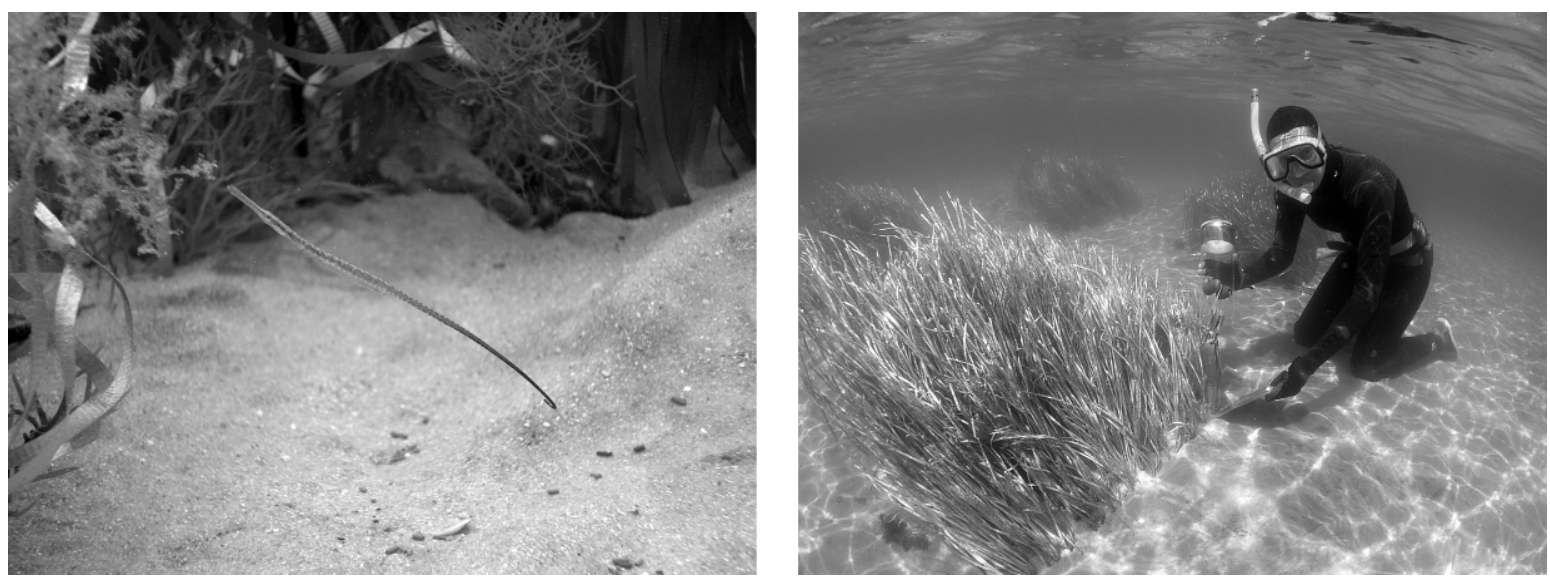

Plate 1. (Left) Pipefish in front of artificial seagrass and (right) diver working in patchy artificial seagrass. Photo credit: P. I. Macreadie.

corner edge over bare sand, 12 ("edge") and 60 and 130 ("interior") $\mathrm{cm}$ into seagrass patches from the corner edge (Fig. 1). Because edge orientation can alter the strength of edge responses in seagrass (Tanner 2003), plankton samples were distributed along four orientations (Fig. 1). The effects of block, position, and orientation were compared in a fully factorial ANOVA. Block was treated as a random factor, and position and orientation were treated as fixed factors. Post hoc comparisons were made among positions using Tukey's tests. Box plots and normal probability plots were used to test the assumptions of analysis of variance.

Our focal fish species, Stigmatopora argus (pipefish), is a planktivore that feeds almost exclusively $(99.6 \%$ contribution by volume) on crustaceans including copepods (calanoids and cyclopoids), amphipods (gammarid), isopods, cumaceans, mysids, ostracods, and crustacean nauplii (Kendrick and Hyndes 2005). A single response variable of food supply was measured as the total abundance of crustacean prey collected in plankton tube traps (PTTs) constructed to the specifications of Yund et al. (1991). Crustacean prey (i.e., copepods, amphipods, isopods, cumaceans, mysids, ostracods, and crustacean nauplii) collected within PTTs were removed onto a $63-\mu \mathrm{m}$ sieve and counted. Connolly (1994a) used a similar sieve size $(75 \mu \mathrm{m})$ and showed that this was effective for sorting Stigmatopora pipefish prey. PTTs were positioned to capture crustaceans within the seagrass canopy because this is the height at which pipefish feed (Howard and Koehn 1985). PTTs collected crustaceans over three days during October 2007.

\section{Experiment 3: determining the importance of food to fish}

To determine whether positive edge effects on pipefish were caused by higher food abundance at edges, we manipulated food abundance at interiors of continuous $\left(9 \mathrm{~m}^{2}\right)$ patch configurations. Treatment patches were supplemented with live brine shrimp (Artemia salina) and controls were supplemented with seawater that was from the same source as the seawater used to culture shrimp. We predicted higher densities of pipefish in outer than inner positions (i.e., positive edge effects) in controls but higher densities at inner than outer positions (i.e., negative edge effects) or no difference (i.e., neutral response to edges) in food-supplemented treatments.

To dispense seawater and shrimp we developed live Artemia dispensers (LADs). LADs consisted of cylindrical PVC reservoirs (3.5-L capacity) attached to steel fence posts that dispensed liquid via a tube into seagrass using a gravity-fed system. The release was controlled by Turbo-Key Drippers (Toro Australia, Beverley, Australia) that dispensed liquid at a rate of $1 \mathrm{~L} / \mathrm{h}$. Shrimp were kept live and suspended within LADs using portable aerators. The density of shrimp was $2.88 \times$ $10^{6}$ nauplii/L. Patches were dosed with shrimp or seawater for $5 \mathrm{~h}$. Gut content analyses of fish from inner samples of treatment patches were used to confirm that pipefish ate shrimp.

After $5 \mathrm{~h}$ of supplementation, fish were sampled with $1-\mathrm{m}^{2}$ drop nets from outer (southeast corner ASU, 0-1 $\mathrm{m}$ from patch edge) and inner (middle ASU, 1-2 m from patch edge) areas of patches. Choice of the sampling areas and orientations was based on a pilot study that estimated dispersal distance of shrimp using plankton tube traps $(n=7)$ positioned at different distances $(35,105,175 \mathrm{~cm})$ and directions (southeast to northwest) from the release point (i.e., the center of the patch). It was necessary to change the position and sampling area of "outer" and "inner" samples from Experiment 1 to avoid supplementation of outer samples with shrimp.

Two trials of the experiment were performed during January 2008, each having six replicates. The model and analysis for this experiment was the same as in Experiment 1, with trial, treatment (food supplemented or control), and position (inner or outer) as factors. The 


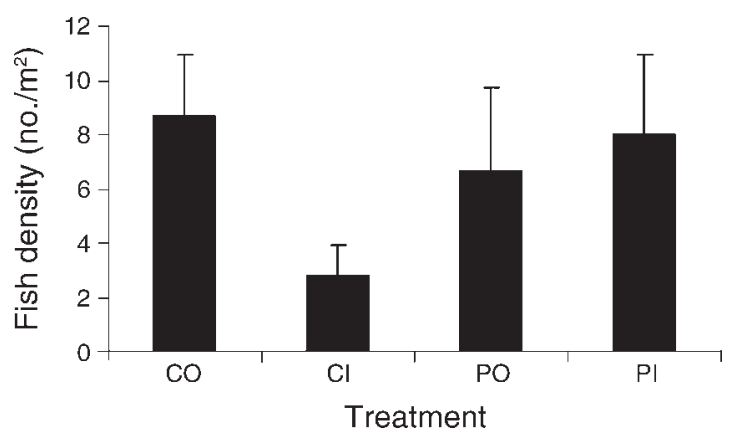

FIG. 2. Density of Stigmatopora argus pipefish (mean $+\mathrm{SE})$ from continuous outer $(\mathrm{CO})$, continuous inner $(\mathrm{CI})$, patchy outer (PO), and patchy inner (PI) treatments. Outer treatments sample an area $0-0.5 \mathrm{~m}$ from the seagrass patch edge; inner treatments sample $0.5-1 \mathrm{~m}$ from the patch edge. Patches are either continuous or patchy in their configuration. Fish density is scaled to $1 \mathrm{~m}^{2}$.

main effect of interest was the difference in pipefish density (response variable) between outer and inner samples in food supplementation treatments and controls.

\section{RESUlts}

\section{Experiment 1: edge effects on fish in seagrass}

Fish assemblages were dominated numerically by spotted pipefish, Stigmatopora argus (65\% of total fish), wide-bodied pipefish, S. nigra (11\%), and recently settled individuals of the leatherjacket Acanthaluteres sp. (11\%). Weedfish (Cristiceps australis; 5\%), girdled gobies (Nesogobius maccullochi; 1.7\%), little rock whiting (Neodax balteatus; 1.1\%), siphonfish (Siphamia cephalotes; $0.6 \%$ ), and knife-snouted pipefish (Hypselognathus rostratus; $0.6 \%$ ) were present but not common enough for analysis; however, it should be noted that these species have the potential to influence the behavior (e.g., through nonconsumptive effects) of the target species (i.e., pipefish).

Only $S$. argus densities showed a consistent response to edges (Appendices A and B), and this species was therefore the focus throughout the remainder of this work. Densities of $S$. argus showed a significant trial by configuration interaction $(P=0.020)$, reflecting a heterogeneous decrease in fish density in patchy configurations among trials. The main interaction of interest was between configuration and position, which occurred for $S$. argus $(P=0.009)$. In continuous configurations there was a significant effect of position, with three times more $S$. argus in outer samples than inner (i.e., $\mathrm{CO}>\mathrm{CI}$, positive edge effects, $P=0.029$ ), but no effect of position in patchy configurations (i.e., $\mathrm{PO}=$ PI, no edge effect; Fig. 2; Appendix B). Also, there was no difference in $S$. argus density among edge samples between patchy or continuous configurations (i.e., $\mathrm{CO}=\mathrm{PO}, \mathrm{PI}$; Appendix B).

\section{Experiment 2: spatial measurements of food abundance across seagrass edges}

A total of 10712 crustaceans was collected, comprising crustacean nauplii (38\%), harpacticoid copepods (24\%), calanoid copepods (20\%), cumaceans (10\%), isopods $(2.5 \%)$, amphipods (2.5\%), ostracods $(2 \%)$, and mysids $(0.5 \%)$. There were significant main effects of block and position (i.e., inner vs. outer) on crustacean abundance, as well as a block $\times$ position interaction $(P=$ 0.010), but no effect of orientation (Appendix C). An inspection of the crustacean abundance among blocks revealed a high degree of spatial variability. There were no obvious patterns for the block $\times$ position interaction when individual blocks were analyzed. This interaction was caused by a shift or lessening of the general pattern in three of the 10 blocks. Crustacean abundance peaked at seagrass edges (i.e., the G12 position) and declined significantly toward seagrass interior and distant sand positions (Fig. 3). From the G12 position, crustacean abundance declined by $8 \%$ and $16 \%$ at the $\mathrm{G} 60$ and G130 positions, respectively, and by $4 \%$ and $15 \%$ at the S12 and S60 sand positions, respectively. Overall, crustacean abundance was $16 \%$ higher at the edges than interiors of seagrass patches.

\section{Experiment 3: food supplementation}

The pilot study (Appendix D) demonstrated elevation of food (shrimp) around the LADs $\left(F_{5,36}=23.5, P<\right.$ 0.001). Shrimp abundance peaked within the immediate vicinity of the release point (i.e., within patch interiors) and declined sharply toward patch edges (note: shrimp were detected across all positions within the patch, including at patch edges).

In both trials, we found strong positive edge effects when food was not supplemented (planned comparison of outer vs. inner, $F_{1,20}=9.42, P=0.004$; Appendix E), with a difference of $4.17 \pm 0.91$ individuals (mean $\pm \mathrm{SE}$ ) between outer $(5.17 \pm 1.37$ individuals $)$ and inner $(1 \pm$ 0.46 individuals) samples. When we supplemented food, the edge effect disappeared (planned comparison, $F_{1,20}=$ $1.22, P=0.275$; Appendix E), with a difference of $1.50 \pm$ 0.67 between outer $(3.5 \pm 1.16)$ and inner $(2 \pm 0.49)$

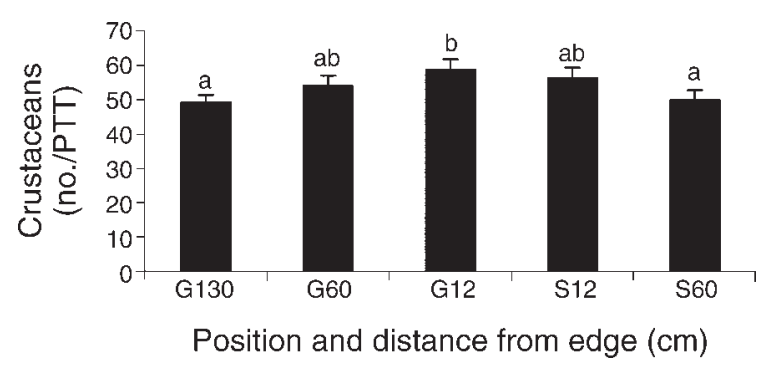

FIG. 3. Abundance (mean $+\mathrm{SE}$ ) of crustaceans (all species pooled) collected in plankton tube traps (PTTs) across seagrass patch positions. Positions are indicated by their distance into seagrass $(\mathrm{G})$ or sand $(\mathrm{S})$ from the patch edge. Letters above bars indicate position effects, and positions with the same letters are not significantly different $(P>0.05)$. 
samples. Gut content analyses confirmed that $S$. argus individuals from inner samples of food-supplemented patches were consuming shrimp (in the order of hundreds of individuals) and that fish from the outer samples did not consume shrimp. This supported the findings of the pilot study that shrimp released from LADs were localized within the middle ASU of the patch. The position by trial interaction (Appendix E) was caused by stronger edge effects for controls in the first trial, and stronger effects of food supplementation in the second trial (note: the patterns did not change, only the strength of the effects).

\section{DisCUSSION}

Our study strongly suggests that Stigmatopora argus, the commonest fish inhabitant of seagrass beds in Port Phillip Bay, is more abundant at seagrass patch edges because of greater food availability. This result is consistent with a resource distribution model, where resources concentrate at edges or where edges provide greatest access to resources from neighboring, nonpreferred habitat (Ries and Sisk 2004). Pipefish existed within artificial seagrass habitat surrounded by lower quality habitat (i.e., bare sand; Edgar et al. 1994, Jenkins et al. 1997a, Jenkins and Wheatley 1998). The key resource for pipefish was therefore seagrass, followed by food within seagrass, specifically, small crustaceans. The majority of crustaceans consumed by S. argus (e.g., crustacean nauplii, calanoid copepods) have a planktonic life cycle (Kendrick and Hyndes 2005), which suggests that $S$. argus may rely on water currents for food. Seagrass limits edge permeability (Fonseca et al. 1982, Peterson et al. 2004) and therefore has the potential to restrict the flow of planktonic crustaceans into seagrass patches (Hendriks et al. 2008), thus creating a distinction between edge and interior zones. At patch edges, we found that crustacean abundance was significantly higher than patch interiors. $S$. argus is a habitat specialist that uses sit-and-wait ambush tactics to prey on passing crustaceans (Howard and Koehn 1985), so at edges they may have greater access to prey. Food supplementation in patch interiors reduced positive edge effects because, it seems, some $S$. argus individuals respond by moving to patch interiors. This provided experimental support that food, as a resource, contributed to positive edge effects, either directly or indirectly, in $S$. argus pipefish.

In Experiment 1, we detected positive edge effects for $S$. argus in continuous configurations, but not in patchy configurations. This suggests that $S$. argus perceived patchy configurations entirely as edge habitat (sensu Attrill et al. 2000), and that edge thickness was $<0.5 \mathrm{~m}$ (drop nets were $0.5 \times 0.5 \mathrm{~m}$ ). Smith et al. (2008) also found positive edge effects for $S$. argus, as well as its close relative, S. nigra. Studies that detect edge effects in seagrass fish are otherwise rare. A recent review (Connolly and Hindell 2006) reported just four studies detecting negative edge effects in seagrass fish and none detecting positive edge effects.

In Experiment 2, we demonstrated that crustaceans were more abundant at seagrass edges and lessened toward sand and seagrass interiors. Terrestrial models predict a similar response when resources are concentrated at edges (Ries and Sisk 2004). Crustacean abundance decreased when moving from edges to interiors, but this difference only became significant at a distance of $130 \mathrm{~cm}$ from edges. This finding contrasts with that of Tanner (2005), who reported positive edge effects for crustaceans at distances of $0.25-1 \mathrm{~m}$ from edges of Zostera seagrass meadows. However, Tanner (2005) used cores to sample a vertical profile of water and provide an instantaneous measure of abundance; we used plankton tube traps that passively sample though time at a fixed height. Tanner (2005) also sampled crustaceans $>1 \mathrm{~mm}$ in size, whereas we sampled those $>63 \mu \mathrm{m}$. Smaller crustaceans (i.e., $<1 \mathrm{~mm}$ ) have less capacity for active movement and therefore have a distribution that is primarily determined by water currents (Fonseca and Bell 1998). This means that they are more likely to have a broader distribution across edges and a thicker edge effect. Had the thickness of the edge effect been smaller, say within $60 \mathrm{~cm}$ of the edge, then the edge effects for $S$. argus in Experiment 1 may have been even stronger. It is important to keep in mind that plankton tube traps have certain sampling biases (Yund et al. 1991), and they are unlikely to provide a completely accurate representation of the food availability to pipefish (e.g., due to differences in the swimming behavior of some prey). We recommend that the crustacean abundance estimates be treated as indicative only.

The edge effects observed for pipefish (Experiment 1) and prey abundance (Experiment 2) varied markedly. The difference in pipefish abundance between edges and interiors was threefold, whereas the variation in prey abundance was only $8 \%$. Furthermore, significant edge effects for prey abundance occurred further into seagrass interiors (i.e., at G130 position), yet the variation in prey abundance remained small (16\%). If fish distribute themselves according to an ideal free distribution (Fretwell and Lucas 1970), then it is possible that pipefish sense and respond to small differences in food abundance; several studies on pipefish indicate that this may be the case (e.g., Ryer 1988, Garcia et al. 2005). It is also expected that high abundances of pipefish at edges will cause reductions in prey abundance at edges such that the prey differential needed to maintain the fish density will look smaller because it does not include prey that were eaten by pipefish (further work using predator exclusions would be needed to validate this hypothesis). A further possibility is that pipefish distributed themselves along edges to increase their foraging efficiency, as opposed to positioning themselves relative to food abundance per se. For example, Flynn and Ritz (1999) showed that 
seahorses (another syngnathid fish with similar feeding strategy to pipefish) increased their capture success at seagrass patch edges by grasping seagrass fronds with their tails and leaning into open water to prey on mysid swarms. Ultimately, the trends in food abundance provided by Experiment 2 provided some evidence that resources underlie the distribution pattern of fish, but the evidence is not conclusive. We undertook a manipulative approach in Experiment 3 to provide a more robust test of our prediction.

In Experiment 3, we manipulated food abundance at patch interiors and found that edge effects for $S$. argus were eliminated in patches supplemented with food (i.e., fish abundance decreased in outer positions and increased at inner positions). This provided supporting evidence that $S$. argus are more abundant at edges due to greater availability of food. It also demonstrated that reduced densities of $S$. argus at patch interiors can be reversed following food addition. Gut content analyses confirmed that $S$. argus collected from inner positions of food-supplemented treatments were consuming shrimp. In the food-supplemented treatments, there was a food concentration gradient that is likely to have attracted fish inward (from edges to interiors). The higher quality and quantity of food supplied through our additions may have provided incentive for fish to follow the food trail toward patch interiors rather than consume naturally supplied food (which was unchanged in the experiment). There was no overall increase in $S$. argus abundance in food-supplemented treatments, only a shift in the density of individuals at inner and outer positions; this indicates that the observed pattern is unlikely to have arisen from colonization by fish from outside treatment patches.

Experimental demonstrations of the role of resources as a mechanism causing edge effects are rare, and our results are consistent with a resource distribution model. The possibility exists, however, that indirect effects could generate the same predicted response (Schmitt et al. 2009). For example, addition of food could cause competitive release or a manifestation of "apparent competition" with some unrecognized competitor that resides in the inner areas of seagrass beds. Such potential confounding effects are difficult to identify (Willems and Hill 2009), and we have no candidate species for such effects. A response by fish to changing resource levels is by far the most parsimonious explanation. Like Silver et al. (2000), our findings suggest that patch configuration affected the distribution of organisms through its influence on resource availability. This finding has important implications for processes that alter patch configuration, such as habitat fragmentation. Habitat fragmentation is a growing concern for both terrestrial (Debinski and Holt 2000, Fahrig 2003) and aquatic ecologists (Eggleston et al. 1999, Hovel and Lipcius 2001, Johnson and Heck 2006). The study of habitat fragmentation can provide important links between concepts and principles of landscape ecology and the practice of landscape architecture and planning (Collinge 1996). Our findings imply that a dominant seagrass pipefish will benefit from habitat fragmentation per se because it increases the amount of edge habitat. While we do not advocate the fragmentation of habitat as a conservation tool (because fragmentation is generally accompanied by habitat loss), we do suggest that patchy configurations may provide an optimal configuration for species that demonstrate positive edge effects. Further work is needed to assess the long-term demographic responses of such species to patchy environments, such as the potential for reduced fecundity in patchy environments (Caley et al. 2001) or increased predation (Hovel and Lipcius 2001, Laurel et al. 2003, Haas et al. 2004).

\section{ACKNOWLEDGMENTS}

We thank F. Warry, T. Smith, A. O'Brien, R. Watson, J. Smith, M. Palmer, M. Wright, A. Macreadie, and M. Bairstow for field assistance, and the people of Ability Works Australia for constructing ASUs. We are grateful for funding through an Australian Research Council Discovery Grant (R. Connolly, J. Hindell, G. Jenkins), a CSIRO Postgraduate Scholarship (P. Macreadie with D. Smith), a Nancy Millis Postgraduate Research Award (P. Macreadie), a Holsworth Wildlife Foundation Grant (P. Macreadie), and a Norman Wettenhall Foundation Grant (P. Macreadie). Comments from two anonymous reviewers greatly improved this manuscript. All research was conducted under University of Melbourne Animal Ethics and DPI Fisheries permits. Research was conducted using the facilities of the Victorian Marine Science Consortium.

\section{Literature Cited}

Attrill, M. J., J. A. Strong, and A. A. Rowden. 2000. Are macroinvertebrate communities influenced by seagrass structural complexity? Ecography 23:114-121.

Bell, J. D., A. S. Steffe, and M. Westoby. 1985. Artificial seagrass: how useful is it for field experiments on fish and macroinvertebrates? Journal of Experimental Marine Biology and Ecology 90:171-177.

Blake, S., and D. Ball. 2001. Victorian marine habitat database: seagrass mapping of Port Phillip Bay. Geospatial Systems Section, Marine and Freshwater Resources Institute Report Number 39. Marine and Freshwater Resources Institute, Queenscliff, Australia.

Bologna, P. A. X. 2006. Assessing within habitat variability in plant demography, faunal density, and secondary production in an eelgrass (Zostera marina L.) bed. Journal of Experimental Marine Biology and Ecology 329:122-134.

Bostrom, C., E. L. Jackson, and C. A. Simenstad. 2006. Seagrass landscapes and their effects on associated fauna: a review. Estuarine Coastal and Shelf Science 68:383-403.

Bullard, S. G., and M. E. Hay. 2002. Plankton tethering to assess spatial patterns of predation risk over a coral reef and seagrass bed. Marine Ecology Progress Series 225:17-28.

Caley, M. J., K. A. Buckley, and G. P. Jones. 2001. Separating ecological effects of habitat fragmentation, degradation, and loss on coral commensals. Ecology 82:3435-3448.

Clements, F. E. 1907. Plant physiology and ecology. Holt, New York, New York, USA.

Collinge, S. K. 1996. Ecological consequences of habitat fragmentation: implications for landscape architecture and planning. Landscape and Urban Planning 36:59-77.

Connolly, R. M. 1994a. Removal of seagrass canopy: effects on small fish and their prey. Journal of Experimental Marine Biology and Ecology 184:99-110. 
Connolly, R. M. 1994b. The role of seagrass as preferred habitat for juvenile Sillaginodes punctata (Cuv and Val) (Sillaginidae, Pisces): habitat selection or feeding. Journal of Experimental Marine Biology and Ecology 180:39-47.

Connolly, R. M., and J. S. Hindell. 2006. Review of nekton patterns and ecological processes in seagrass landscapes. Estuarine Coastal and Shelf Science 68:433-444.

Cronin, J. T. 2009. Habitat edges, within-patch dispersion of hosts, and parasitoid oviposition behavior. Ecology 90:196207.

Debinski, D. M., and R. D. Holt. 2000. A survey and overview of habitat fragmentation experiments. Conservation Biology $14: 342-355$.

Duarte, C. M. 2002. The future of seagrass meadows. Environmental Conservation 29:192-206.

Edgar, G. J., C. Shaw, G. F. Watson, and L. S. Hammond. 1994. Comparisons of species richness, size-structure and production of benthos in vegetated and unvegetated habitats in Western Port, Victoria. Journal of Experimental Marine Biology and Ecology 176:201-226.

Eggleston, D. B., W. E. Elis, L. L. Etherington, C. P. Dahlgren, and M. H. Posey. 1999. Organism responses to habitat fragmentation and diversity: habitat colonization by estuarine macrofauna. Journal of Experimental Marine Biology and Ecology 236:107-132.

Ewers, R. M., and R. K. Didham. 2006. Confounding factors in the detection of species responses to habitat fragmentation. Biological Reviews 81:117-142.

Fagan, W. E., R. S. Cantrell, and C. Cosner. 1999. How habitat edges change species interactions. American Naturalist 153: 165-182.

Fahrig, L. 2003. Effects of habitat fragmentation on biodiversity. Annual Review of Ecology, Evolution, and Systematics 34:487-515.

Fazey, I., J. Fischer, and D. B. Lindenmayer. 2005. What do conservation biologists publish? Biological Conservation 124: 63-73.

Flynn, A. J., and D. A. Ritz. 1999. Effect of habitat complexity and predatory style on the capture success of fish feeding on aggregated prey. Journal of the Marine Biological Association of the United Kingdom 79:487-494.

Fonseca, M. S., and S. S. Bell. 1998. Influence of physical setting on seagrass landscapes near Beaufort, North Carolina, USA. Marine Ecology Progress Series 171:109-121.

Fonseca, M. S., J. S. Fisher, J. C. Zieman, and G. W. Thayer. 1982. Influence of the seagrass, Zostera marina L., on current flow. Estuarine Coastal and Shelf Science 15:351-358.

Fretwell, S. D., and H. L. Lucas. 1970. On territorial behavior and other factors influencing habitat distribution in birds. I. Theoretical development. Acta Biotheoretica 19:16-36.

Garcia, A. M., R. M. Geraldi, and J. P. Vieira. 2005. Diet composition and feeding strategy of the southern pipefish Sygnathus folletti in a widgeon grass bed of the Patos Lagoon Estuary, RS, Brazil. Neotropical Ichthyology 3:427-432.

Haas, H. L., K. A. Rose, B. Fry, T. J. Minello, and L. P. Rozas. 2004. Brown shrimp on the edge: linking habitat to survival using an individual-based simulation model. Ecological Applications 14:1232-1247.

Hendriks, I. E., T. Sintes, T. J. Bouma, and C. M. Duarte. 2008. Experimental assessment and modeling evaluation of the effects of the seagrass Posidonia oceanica on flow and particle trapping. Marine Ecology Progress Series 356:163173.

Hovel, K. A., M. S. Fonseca, D. L. Myer, W. J. Kenworthy, and P. E. Whitfield. 2002. Effects of seagrass landscape structure, structural complexity and hydrodynamic regime on macrofaunal densities in North Carolina seagrass beds. Marine Ecology Progress Series 243:11-24.

Hovel, K. A., and R. N. Lipcius. 2001. Habitat fragmentation in a seagrass landscape: patch size and complexity control blue crab survival. Ecology 82:1814-1829.
Hovland, N., H. P. Andreassen, and R. A. Ims. 1999. Foraging behaviour of the root vole Microtus oeconomus in fragmented habitats. Oecologia 121:236-244.

Howard, R. K., and J. D. Koehn. 1985. Population dynamics and feeding ecology of pipefish (Sygnathidae) associated with eelgrass beds of Western Port, Victoria. Australian Journal of Marine and Freshwater Research 36:361-370.

Jackson, E. L., A. A. Rowden, M. J. Attrill, S. J. Bossey, and M. B. Jones. 2001. The importance of seagrass beds as a habitat for fishery species. Oceanography and Marine Biology 39:269-303.

Jenkins, G. P., K. P. Black, M. J. Wheatley, and D. N. Hatton. 1997a. Temporal and spatial variability in recruitment of a temperate, seagrass-associated fish is largely determined by physical processes in the pre- and post-settlement phases. Marine Ecology Progress Series 148:23-35.

Jenkins, G. P., M. J. Keough, and P. A. Hamer. 1998. The contributions of habitat structure and larval supply to broadscale recruitment variability in a temperate zone, seagrassassociated fish. Journal of Experimental Marine Biology and Ecology 226:259-278.

Jenkins, G. P., H. M. A. May, M. J. Wheatley, and M. G. Holloway. 1997b. Comparison of fish assemblages associated with seagrass and adjacent unvegetated habitats of Port Phillip Bay and Corner Inlet, Victoria, Australia, with emphasis on commercial species. Estuarine Coastal and Shelf Science 44:569-588.

Jenkins, G. P., and M. J. Wheatley. 1998. The influence of habitat structure on nearshore fish assemblages in a southern Australian embayment: comparison of shallow seagrass, reefalgal and unvegetated sand habitats, with emphasis on their importance to recruitment. Journal of Experimental Marine Biology and Ecology 221:147-172.

Johnson, M. W., and K. L. Heck. 2006. Effects of habitat fragmentation per se on decapods and fishes inhabiting seagrass meadows in the northern Gulf of Mexico. Marine Ecology Progress Series 306:233-246.

Kendrick, A. J., and G. A. Hyndes. 2005. Variations in the dietary compositions of morphologically diverse syngnathid fishes. Environmental Biology of Fishes 72:415-427.

Laurel, B. J., R. S. Gregory, and J. A. Brown. 2003. Predator distribution and habitat patch area determine predation rates on age- 0 juvenile cod Gadus spp. Marine Ecology Progress Series 251:245-254.

Lay, D. W. 1938. How valuable are woodland clearings to birdlife? Wilson Bulletin 50:254-256.

Levin, P., R. Petrik, and J. Malone. 1997. Interactive effects of habitat selection, food supply and predation on recruitment of an estuarine fish. Oecologia 112:55-63.

Macreadie, P. I., J. S. Hindell, G. P. Jenkins, R. M. Connolly, and M. J. Keough. 2009. Fish responses to experimental fragmentation of seagrass habitat. Conservation Biology 23: $644-652$.

Mosk, V., N. Thomas, N. S. Hart, J. C. Partridge, L. D. Beazley, and J. Shand. 2007. Spectral sensitivities of the seahorses Hippocampus subselongatus and Hippocampus barbouri and the pipefish Stigmatopora argus. Visual Neuroscience 24:345-354.

Murcia, C. 1995. Edge effects in fragmented forests: implications for conservation. Trends in Ecology and Evolution 10: $58-62$.

Orth, R. J., et al. 2006. A global crisis for seagrass ecosystems. BioScience 56:987-996.

Peterson, C. H., R. A. Luettich, F. Micheli, and G. A. Skilleter. 2004. Attenuation of water flow inside seagrass canopies of differing structure. Marine Ecology Progress Series 268:8192.

Ries, L., R. J. Fletcher, J. Battin, and T. D. Sisk. 2004. Ecological responses to habitat edges: mechanisms, models, and variability explained. Annual Review of Ecology, Evolution, and Systematics 35:491-522. 
Ries, L., and T. D. Sisk. 2004. A predictive model of edge effects. Ecology 85:2917-2926.

Robbins, B. D., and S. S. Bell. 1994. Seagrass landscapes: a terrestrial approach to the marine subtidal environment. Trends in Ecology and Evolution 9:301-304.

Ryer, C. H. 1988. Pipefish foraging: effects of fish size, prey size and altered habitat complexity. Marine Ecology Progress Series 48:37-45.

Saunders, D. A., R. J. Hobbs, and C. R. Margules. 1991. Biological consequences of ecosystem fragmentation: a review. Conservation Biology 5:18-32.

Schmitt, R. J., S. J. Holbrook, A. J. Brooks, and J. C. P. Lape. 2009. Intraguild predation in a structured habitat: distinguishing multiple-predator effects from competitor effects. Ecology 90:2434-2443.

Silver, P., J. K. Cooper, M. A. Palmer, and E. J. Davis. 2000. The arrangement of resources in patchy landscapes: effects on distribution, survival, and resource acquisition of chironomids. Oecologia 124:216-224.

Smith, T. M., J. S. Hindell, G. P. Jenkins, and R. M. Connolly. 2008. Edge effects on fish associated with seagrass and sand patches. Marine Ecology Progress Series 359:203-213.
Strayer, D. L., M. E. Power, W. F. Fagan, S. T. A. Pickett, and J. Belnap. 2003. A classification of ecological boundaries. BioScience 53:723-729.

Tanner, J. E. 2003. Patch shape and orientation influences on seagrass epifauna are mediated by dispersal abilities. Oikos 100:517-524.

Tanner, J. E. 2005. Edge effects on fauna in fragmented seagrass meadows. Austral Ecology 30:210-218.

Upston, J., and D. J. Booth. 2003. Settlement and density of juvenile fish assemblages in natural, Zostera capricorni (Zosteraceae) and artificial seagrass beds. Environmental Biology of Fishes 66:91-97.

Warry, F. Y., J. S. Hindell, P. I. Macreadie, G. P. Jenkins, and R. M. Connolly. 2009. Integrating edge effects into studies of habitat fragmentation: a test using meiofauna in seagrass. Oecologia 159:883-892.

Willems, E. P., and R. A. Hill. 2009. Predator-specific landscapes of fear and resource distribution: effects on spatial range use. Ecology 90:546-555.

Yund, P. O., S. D. Gaines, and M. D. Bertness. 1991. Cylindrical tube traps for larval sampling. Limnology and Oceanography 36:1167-1177.

\section{APPENDIX A}

Results of four-factor ANOVA tests comparing density of fish sampled among trials, configurations, position, and location of plot configurations (Ecological Archives E091-138-A1).

\section{APPENDIX B}

Results of planned comparisons comparing density of fish among treatments (Ecological Archives E091-138-A2).

\section{APPENDIX C}

Analysis of the effect of block, position, and orientation on the abundance of crustaceans collected in plankton tube traps (Ecological Archives E091-138-A3).

\section{APPENDIX D}

Abundance of Artemia salina collected in plankton tube traps across seagrass patch positions (Ecological Archives E091-138-A4).

\section{APPENDIX E}

Analysis of the effect of trial, treatment (food supplemented or control), and position (inner or outer) on the abundance of Stigmatopora argus pipefish (Ecological Archives E091-138-A5). 